\title{
LOS CONOCIMIENTOS PREVIOS EN LA ALFABETIZACIÓN INICIAL
}

\author{
Luz Emilia Flores Davis ${ }^{l}$
}

\section{Resumen}

La alfabetización inicial constituye un reto para los sistemas educativos por su impacto en el desenvolvimiento de las personas en una sociedad letrada, así como por su importancia para el aprendizaje de las distintas disciplinas. En este ensayo, se presenta una reflexión sobre el papel de los conocimientos previos para generar aprendizajes significativos en el área de lectura y escritura. Esta reflexión es posible a partir del análisis de información respecto a los procesos de construcción de la escritura realizados por niños y niñas de primer año de la Educación General Básica.

Palabras claves: conocimientos previos, lectura y escritura, alfabetización inicial, primer grado.

\section{Abstract}

Initial alphabetization constitutes a challenge for educational systems due to its impact in the behavior of people in a literate society, as its importance for future learming of different disciplines. In this article, the role of previous lnowledge is discussed for the consequent creation of significant leaming areas in reading and writing. This discussion is based on the analysis of the information collected by a study on the construction processes of writing on first grade students.

Keywords: initial alphabetization, reading and writing.

\section{Introducción}

L

a importancia de tomar en cuenta los conocimientos previos de para suscitar aprendizajes es una idea medular del constructivismo, altamente

1 Máster en Educación Superior, ostenta el grado de catedrática universitaria. Ha ocupado los cargos de Directora de Docencia de la Universidad Nacional y Directora de Desarrollo Profesional y Cooperación Universitaria, actualmente se desempeña como investigadora, extensionista y docente en la División de Educación Básica del CIDE y docente en la Maestria en Formación Dancistica del CIDEA. Entre sus publicaciones más recientes destacan trabajos para la Alfabetización de personas adultas. 
difundida en los últimos años. Atribuir sentido a lo que se aprende es una noción fundamental, tanto en un modelo pedagógico cognitivo, como en un modelo pedagógico social. Sin embargo, llevar este principio a la práctica educativa cotidiana constituye un reto para los y las docentes en todos los niveles del sistema educativo.

Lo anterior cobra una importancia especial en el ámbito del primer año de la Educación General Básica, donde muchas veces se llevan a cabo actividades de enseñanza sin tomar en cuenta las construcciones realizadas por los niños y las niñas antes de ingresar a la escuela, o durante el proceso de aprendizaje de la lectura y escritura. Esto con el agravante que significa que si los educandos y las educandas no aprenden a leer y escribir en primer grado, no pueden enfrentarse a un proceso escolar que demanda su dominio para el abordaje de las distintas asignaturas. Por ello, históricamente, la enseñanza de la lectura y la escritura ha merecido una atención especial, y el fracaso en el primer año escolar, por lo general, se traduce en una eventual expulsión del sistema educativo y, en consecuencia, en muchos casos, en causa del analfabetismo de personas jóvenes y adultas.

Por otra parte, el proceso pedagógico para promover el aprendizaje de la lectura y escritura requiere que el educador o la educadora esté en constante conocimiento de la evolución que realizan los niños y las niñas para que su intervención sea oportuna. Los conocimientos previos se modifican constantemente, y la dinámica es tal que necesita que el maestro o la maestra cuente con estrategias que le permitan generar espacios y comunidades de aprendizaje donde afloren esos conocimientos.

También es necesario contar con aulas espaciosas que posibiliten la organización de subgrupos y con muebles apropiados para ello. Otra condición importante para optimizar una labor educativa, que parta de los conocimientos previos, es el número de estudiantes que se atienden por grupo, pues aunque hay estrategias que facultan el diagnóstico de saberes en grupos numerosos, en estos casos, se reduce el nivel de profundidad de análisis.

\section{Enseñanza y aprendizaje}

La enseñanza y el aprendizaje constituyen dos dimensiones interdependientes del proceso pedagógico; sin embargo, el interés y la preocupación docente se centran muchas veces en aspectos relativos a la evaluación sumativa extema. Es innegable la importancia de la evaluación en la práctica pedagógica, 
siempre y cuando se asuma de manera flexible y utilizando además de la modalidad sumativa, la evaluación diagnóstica y la formativa.

Desde un paradigma socioconstructivista que integre los modelos pedagógicos cognitivo y social, la persona es el centro del proceso pedagógico, lo que implica la necesidad de conocer y tener presentes las características de los y las estudiantes y establecer relaciones de respeto a las diferencias, para lo cual son indispensables la evaluación diagnóstica y la formativa.

El ilustre educador costarricense don Marco Tulio Salazar sabiamente solía decir la frase: "Lo afectivo es efectivo". Con ello expresaba su visión humanista de la educación y presentaba los fundamentos de un enfoque y una estrategia para trabajar en el aula. La dimensión afectiva es, sin lugar a dudas, el marco para un desarrollo didáctico centrado en los seres humanos y es requisito para el establecimiento de un adecuado clima de clase.

Para acercarse al conocimiento de las características del estudiantado, es necesario tener en cuenta aspectos relativos a su contexto, así como sus particularidades, intereses, necesidades y capacidades.

Cabe destacar aquí que la información obtenida mediante el diagnóstico de las situaciones que viven los y las estudiantes, así como la valoración de sus condiciones individuales, deben servir para tomar las decisiones necesarias para generar procesos de aprendizaje que consideren su entorno y partan de los saberes e ideas previas; de esta manera garantizar su avance y no para justificar el fracaso escolar.

Muchas veces se atribuyen las dificultades para aprender a leer y escribir a la falta de apoyo de los padres y las madres, o a las condiciones económicas o culturales de la familia, circunstancias que repercuten en el desarrollo académico de los niños y las niñas, pero que más bien deben convertirse en motivadoras de la labor docente. Entre menos ayuda para aprender tenga un niño o una niña en su hogar, mayor es la responsabilidad y compromiso que tiene que asumir el o la docente y la escuela.

La institución educativa tiene la responsabilidad social de realizar todas las acciones a su alcance para compensar los desequilibrios en las oportunidades de aprendizaje en cualquiera de sus niveles.

No obstante, aunque es común que el educador o la educadora acepte que las características de sus estudiantes, así como las condiciones de sus hogares, inciden en la efectividad de su labor, aún persiste una tendencia a uniformar los procesos pedagógicos y con ello irrespetar el derecho de cada persona de entender y conceptuar los nuevos aprendizajes según sus propias experiencias. 
Lo anterior es especialmente evidente en el primer año de la Educación General Básica, donde la utilización de métodos tradicionales para la enseñanza de la lectura y escritura supone que todos los niños y las niñas piensan lo mismo y de manera sincrónica. Quienes trabajan de esa forma, se apegan a los pasos metodológicos que presenta un determinado método, desconociendo los procesos individuales y los conocimientos previos de sus estudiantes.

\section{Revisión teórica de los niveles de conceptualización de la escritura}

Para identificar lo que conoce un o una estudiante sobre un tema específico, es menester saber cuál es la lógica de la estructura de esa disciplina y cómo se construye su aprendizaje.

En el ámbito de la escritura, los resultados de las investigaciones psicogenéticas de Emilia Ferreiro, discípula de Piaget, tienen un impacto trascendental en la enseñanza de la lectura y escritura: explican muchos fenómenos que los y las docentes habían observado durante años en sus estudiantes sin poder entender las construcciones que se estaban llevando a cabo en el proceso de adquisición del sistema alfabético. Los niveles para la construcción de la escritura que formula Ferreiro se presentan en el texto de Gómez (1983) y se resumen a continuación:

\section{Nivel concreto}

Las personas que se encuentran en el nivel concreto no han comprendido el carácter simbólico de la escritura. No diferencian dibujo de escritura.

\section{Nivel simbólico o presilábico}

En este nivel, la persona ya considera que la escritura remite a un significado. Se plantea las siguientes suposiciones:

- Hipótesis del nombre: asume que los textos dicen los nombres de los objetos.

- $\quad$ Hipótesis de cantidad: considera que para que una palabra se pueda leer debe tener tres grafías o más.

- $\quad$ Hipótesis de variedad: piensa que un texto, para ser leído, debe estar formado por signos variados. 


\section{Nivel lingüistico}

La persona ha descubierto la relación entre el texto y los aspectos sonoros del habla. El proceso seguido es el siguiente:

- Hipótesis silábica inicial: realiza un análisis silábico de los nombres y, por lo tanto, escribe una letra o pseudoletra por cada sílaba emitida.

- Hipótesis silábica estricta: en este momento mantiene la escritura de una letra por cada sílaba de la palabra, pero ahora esa letra tiene un valor sonoro estable, o sea, la letra que escribe coincide con la vocal o con la consonante que efectivamente forman la sílaba.

- Hipótesis de transición silábica-alfabética: la persona que construye esta hipótesis realiza un razonamiento silábico para algunas de las sílabas de la palabra y en otras sílabas hace un razonamiento alfabético.

- Hipótesis alfabética: establece una correspondencia entre los fonemas que forman una palabra y las letras necesarias para escribirla.

Posteriormente a los trabajos de Emilia Ferreiro, Raúl Hachén publica en el año 2002, sus investigaciones referidas a las conceptualizaciones que realizan las personas en torno a la estructura de la sílaba en el proceso de alfabetización, demostrando que el proceso de construcción no concluye con la hipótesis alfabética, entendida como proceso arbitrario e impredecible, sino más bien que continúa de manera sistemática para comprender la estructura de la sílaba utilizando las hipótesis de cantidad, de variedad y de posición, pero ahora no sobre la palabra en su totalidad, sino más bien en el interior de la sílaba.

Hachén (2002) propone una subdivisión de la hipótesis alfabética de la siguiente manera:

- Alfabético inicial: donde se consolida el esquema consonante - vocal para todas las sílabas de la palabra.

- Alfabético medio: en este momento, la persona realiza una proyección en el seno de la rima o del ataque de la hipótesis de cantidad y elabora, entonces, otras producciones silábicas tales como consonante - vocal - consonante, o consonante - consonante - vocal.

- Alfabético (estricto): la persona comprende que existe la posibilidad de diferentes realizaciones silábicas en una misma palabra y habilita todos 
los espacios funcionales de la estructura de la sílaba, a saber: consonante - consonante - vocal - consonante - consonante.

Un esquema de lo expuesto hasta aquí se presenta a continuación.

\section{Niveles de conceptualización de la escritura}

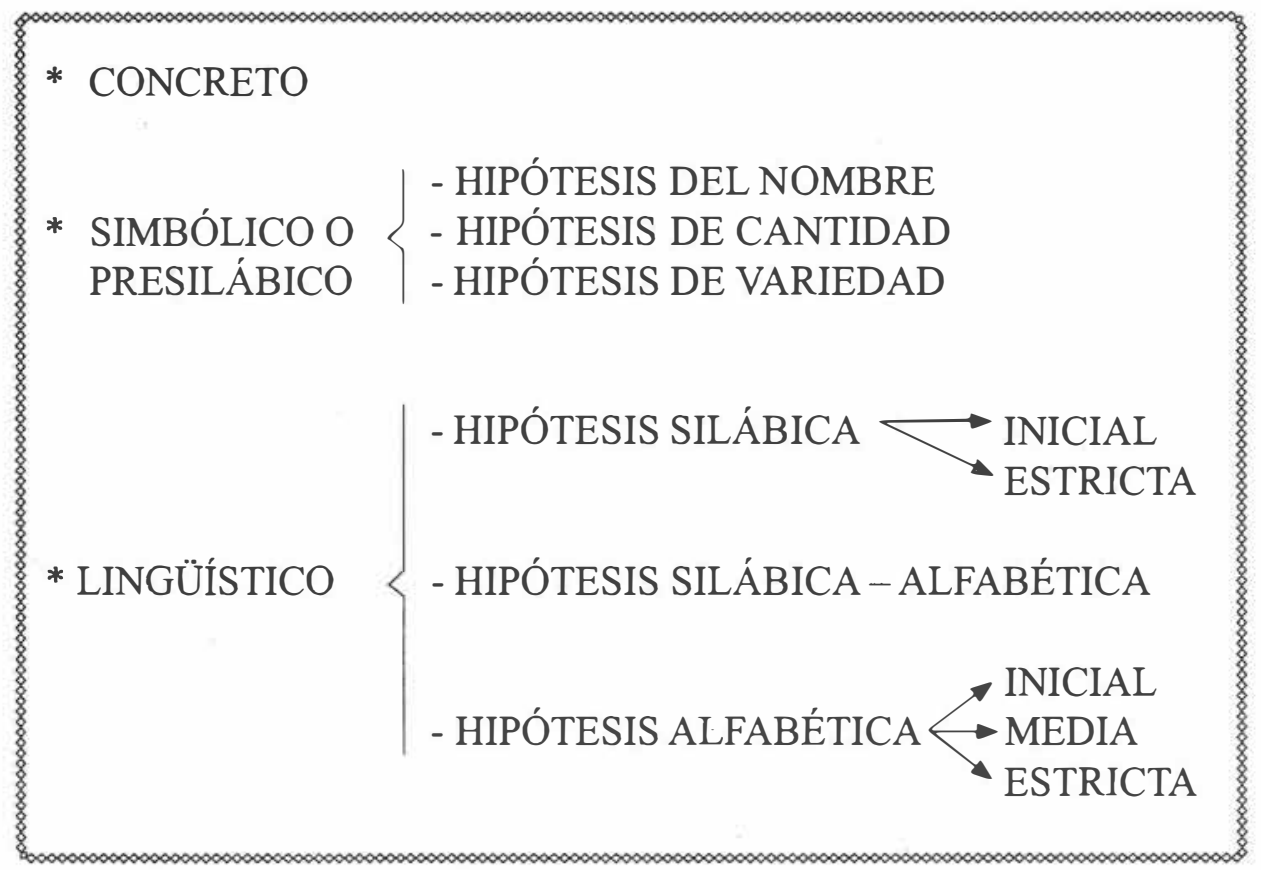

¿Qué piensan los niños y las niñas?

En el mes de abril del año 2006, los y las estudiantes del curso Enfoques Contemporáneos de Lectura y Escritura, de la División de Educación Básica del CIDE de la Universidad Nacional, realizaron una indagación que abarcó mil sesenta y cinco niños y niñas de primer grado. Se asistió a cuarenta y siete escuelas y cada estudiante de la universidad trabajó con un promedio de dieciocho niños o niñas. Los métodos más utilizados por los y las docentes de los grupos visitados fueron el método Silábico, el Ecléctico y el Natural Integral.

El trabajo demuestra que los niños y las niñas que asisten al primer grado se encuentran en diversos niveles de conceptualización de la escritura, lo 
que significa que cuando la maestra está pretendiendo que escriban una palabra, frase u oración, de manera alfabética, según lo establecen los métodos de enseñanza, algunos de ellos o ellas están pensando que la palabra se escribe de otra forma, según sus hipótesis, lo cual lleva a la copia sin comprensión, superponiendo la información que da el o la docente a las estructuras cognitivas desarrolladas por sus estudiantes. En otras palabras, no se está partiendo del conocimiento previo y, por lo tanto, no se está favoreciendo la construcción de aprendizajes significativos.

En los cuadros siguientes, se ofrece un resumen de los resultados de esa indagación.

\section{Cuadro $\mathbf{N}^{0} 1$}

Niveles de conceptualización de la escritura de niños y niñas de primer año

\begin{tabular}{|c|c|c|}
\hline NIVEL & NÚMERO & $\%$ \\
\hline CONCRETO & 36 & 3 \\
\hline PRESILÁBICO & 453 & 42 \\
\hline SILÁBICO & 130 & 12 \\
\hline SILÁBICO-ALFABÉTICO & 114 & 11 \\
\hline ALFABÉTICO & 332 & 32 \\
\hline TOTAL & 1065 & 100 \\
\hline
\end{tabular}




\section{CUADRO $\mathbf{N}^{\circ} \mathbf{2}$}

Niveles y subniveles de conceptualización de la escritura de niños y niñas de primer año

\begin{tabular}{|c|c|c|}
\hline NIVEL & NÚMERO & $\%$ \\
\hline CONCRETO & 36 & 3 \\
\hline PRESILÁBICO & 453 & 42 \\
\hline SILÁBICO INICIAL & 69 & 6 \\
\hline SILÁBICO ESTRICTO & 61 & 6 \\
\hline SILÁBICO-ALFABÉTICO & 114 & 11 \\
\hline ALFABÉTICO INICIAL & 91 & 9 \\
\hline ALFABÉTICO MEDIO & 96 & 9 \\
\hline ALFABÉTICO ESTRICTO & 145 & 14 \\
\hline TOTAL & 1065 & 100 \\
\hline
\end{tabular}


Destaca en la información recolectada, que el $42 \%$ de los niños y las niñas se encuentra, al mes de abril, en el nivel presilábico, lo que requeriría que sus docentes enfatizaran un trabajo de análisis silábico antes de trabajar con letras.

En la indagación llevada a cabo, el $23 \%$ de los niños y las niñas se encuentra en el nivel silábico o en transición silábico-alfabético, lo que indica la necesidad de propiciar que descubran los valores sonoros del habla y fortalecer, como en todos los niveles, que utilicen la escritura como medio de expresión y de comunicación.

Como se observa en los cuadros anteriores, solamente el $32 \%$ de los niños y las niñas participantes se encuentra en el nivel alfabético, que les permite comprender que la sílaba está formada por más de un elemento y seguir, entonces, el recorrido que le ofrecen los métodos tradicionales de enseñanza.

\section{Estrategias del o la docente}

Como ya se dijo, un trabajo pedagógico que se enmarque en el constructivismo requiere la consideración de los conocimientos previos de los y las estudiantes, los cuales una vez identificados deben ubicarse en la estructura teórica de la disciplina en estudio, para determinar el proceso que debe seguir el educando o la educanda y, por consiguiente, las acciones pedagógicas de la intervención docente, atendiendo las características de cada estudiante y su contexto.

Conocer los distintos niveles de conceptualización de la escritura y tener presentes los procesos que está llevando a cabo cada estudiante, constituyen el punto de partida para seleccionar las acciones docentes adecuadas. Entre las estrategias más efectivas cabe destacar el juego, partir del nombre propio, así como propiciar el trabajo entre personas que se encuentran en niveles de conceptualización cercanos, favorecen las construcciones, pues la colaboración entre pares apoya el desarrollo de los y las estudiantes al generar el conflicto cognitivo y la construcción del aprendizaje. Ayudar a pensar no es una tarea exclusiva del o la docente, pero generar las condiciones que favorezcan relaciones positivas entre compañeros y compañeras es una responsabilidad que se debe asumir de manera consciente.

En el marco de las estrategias citadas, seguidamente se expone una serie de actividades que pueden realizar niños, niñas, jóvenes o personas adultas atendiendo el nivel de conceptualización de la escritura en que se encuentren. 
Nivel concreto

Para propiciar que quienes están en el nivel concreto avancen al presilábico, es fundamental la realización de diversas actividades de lectura, por ejemplo, solicitarles que lean un cuento a partir de sus imágenes y posteriormente leérselos, utilizando el texto escrito y señalando las palabras. Otra actividad, que favorece la comprensión del carácter simbólico de la escritura, es entregar a cada participante una tarjeta con su nombre, la cual cada quien debe colocar en la pared del aula y dejarla ahí al retirarse de la escuela. Ello favorece la comprensión de que aunque la persona se retira del salón, simbólicamente, permanece en él.

\section{Nivel presilábico}

Algunas actividades, que pueden favorecer que las personas descubran la correspondencia entre lo que se habla y lo que se escribe, son aquellas donde se asocien palabras e imágenes y se juegue a palmear las sílabas que la componen, o mejor aún, saltar o expresar de diversas maneras la división silábica. Otras actividades, que favorecen esos descubrimientos, son el uso de rimas y su análisis y diversos juegos, donde se utilicen sílabas para buscar palabras que las contengan. Quienes recién inician un pensamiento presilábico consideran que existe relación entre el número de grafías que se necesitan para escribir un nombre y el tamaño del objeto que este simboliza; por lo tanto, suponen, por ejemplo, que toro necesita más letras que maripo$s a$, razón que justifica la importancia de realizar diferentes juegos, donde se representen las sílabas con las que se expresan oralmente esas palabras.

\section{Nivel silábico-alfabético}

Se favorece el avance hacia el nivel alfabético creando situaciones de conflicto cognitivo para lo que es útil el uso de palabras bisílabas que contengan las mismas vocales, lo que dará la oportunidad de cuestionar la hipótesis de cantidad, así como palabras que tengan la misma vocal en todas sus sílabas para cuestionar la hipótesis de variedad.

Así, la consolidación de la hipótesis alfabética es recomendable para realizar juegos utilizando las letras que forman una palabra, por ejemplo, buscar palabras que inician con cada una de las letras del nombre propio, realizar crucigramas, jugar ahorcado, entre otros. 


\section{Nivel alfabético}

Es necesario recordar el proceso de construcción alfabética y no caer en el error de considerar como problemas de ortografía, o de omisión de letras por descuido, producciones que responden a la lógica de los y las estudiantes.

En este nivel, es aconsejable llevar a cabo juegos para el conocimiento de reglas ortográficas y enfatizar el uso de la escritura, con propósitos funcionales de comunicación y expresión, tales como la confección de cartas, poesías, cuentos.

El papel del o la docente en todos los niveles de conceptualización de la escritura es, entonces, propiciar la reflexión y el descubrimiento, destacando las producciones que se van elaborando, favoreciendo el análisis por medio de la comparación de semejanzas y diferencias, y utilizando preguntas que cuestionen las ideas de los alumnos y las alumnas.

Cobra gran importancia la elaboración de diversos tipos de textos, para lo cual el educador o la educadora debe favorecer la expresión oral de las vivencias de sus estudiantes e incentivar que representen sus pensamientos y sentimientos mediante el tipo de texto que consideren más adecuado para sus necesidades (Flores y Sánchez, 2004).

Es interesante destacar con Sánchez et al. (2001) que el contexto es también un texto, y por lo tanto:

"Al describirlo y analizarlo recurrimos a las mismas operaciones mentales:

- partimos de nuestros conocimientos previos,

- $\quad$ establecemos relaciones de lo nuevo con nuestras vivencias anteriores,

- encontramos semejanzas y diferencias,

- muchas veces nos anticipamos a los hechos,

- establecemos relaciones entre los elementos que lo integran” (p. 15).

\section{Más allá de las letras}

La alfabetización inicial va más allá de las letras, pues implica una comprensión crítica de la realidad social, política, económica y cultural en la que está inmerso o inmersa quien aprende. Freire y Macedo (1989) indican al respecto: "La lectura de la realidad siempre precede a la lectura de la 
palabra, así como la lectura de la palabra implica una continua lectura de la realidad".

El respeto y la coherencia entre lo que se dice y lo que se hace, por ejemplo, son valores que pueden ser comprendidos por niños y niñas desde muy corta edad. Las experiencias, así como los intereses de los y las participantes en un proceso pedagógico, son aspectos que deben tenerse presentes en la labor docente.

El respeto y la valoración de los conocimientos previos se constituyen, entonces, no sólo en un requerimiento didáctico, sino también en un componente esencial de un modelo pedagógico social-cognitivo, que busca la formación de personas críticas, creativas, autónomas, capaces de leer la palabra y leer su realidad, capaces de arriesgarse a escribir las palabras y escribir su propia transformación. 


\section{Referencias}

Flores, L. E. y Sánchez, M. (2004). Alfabetización de niños, niñas y personas adultas: Componente indispensable en la formación docente. Lectura y Escritura en Voces Latinoamericanas.

Freire, P. y Macedo, D. (1989). Alfabetización: lectura de la palabra y lectura de la realidad. España: PAIDÓS.

Gómez, P. (1983). Propuesta para el aprendizaje de la lengua escrita. México: SEP-OEA.

Hachén, R. (2002). “Conocimiento lingüístico y reflexión metalingüística”. Lectura y Vida, 23(2).

Sánchez, M., Flores, L. E. y Céspedes, E. (2001). Alfabetización: transitando entre el contexto social y el texto escrito. Costa Rica: OIM, MEP, USAID, UNA. 